\title{
EPIGRAFÍA MEDIEVAL DEL MUSEO DIOCESANO REGINA COELI (SANTILLANA DEL MAR, CANTABRIA)
}

\section{MEDIEVAL EPIGRAPHY OF DIOCESAN MUSEUM REGINA COELI (SANTILLANA DEL MAR, CANTABRIA)}

\author{
Alberto Peña Fernández \\ Yacimientos y centros culturales de Cantabria \\ Sociedad Regional de Cultura y Deporte \\ Consejería de Educación, Cultura y Deporte
}

Resumen: Entre los fondos que integran las diferentes colecciones del Museo Diocesano "Regina Coeli", se encuentran varias inscripciones medievales sobre soportes pétreos, principalmente estelas y fragmentos de lápidas funerarias procedentes de necrópolis o reformas efectuadas en algunos templos, junto a una celosía epigráfica, y, metálicos, especialmente objetos litúrgicos que, procedentes de parroquias de la Diócesis, han sido trasladados al museo para evitar su deterioro o expoliación. En este último caso, se trata de cálices, custodias, píxides y cruces procesionales, labrados en plata o cobre.

Las dieciséis inscripciones que se presentan no forman parte de una colección independiente del museo, sino que se incluyen en dos de sus principales colecciones, arqueología y platería española. Se pretende la lectura y edición crítica de sus textos, atendiendo a las recientes tendencias de la investigación epigráfica que conciben la inscripción como un medio de comunicación de carácter publicitario en el que intervienen tres elementos -autor, rogatario y destinatario- organizados en dos fases, actio y conscriptio epigráficas. En cuanto a la tipología de epígrafes establecida por algunos autores en analogía con la ciencia documental $\mathrm{y}$, en relación a los grupos más frecuentes en las colecciones epigráficas, diferenciaremos entre epitaphia, suscriptiones, invocationes y donationes.

Palabras Clave: Inscripción, Edad Media, Museo Diocesano Regina Coeli, estela, epitafio, píxide, cruz procesional.

Abstract: Between the funds that integrate the different collections of the Diocesan Museum "Regina Coeli", they find several medieval inscriptions on stony supports, principally estelas and fragments of funeral tablets proceeding from necropolis or reforms effected in some temples, close to an epigraphic lattice, and metal-workers as some objects liturgical that proceeding from parishes of the Diocese have been moved to the museum to avoid his deterioration or spoliation. In the latter case, it is a question of chalices, custodies, píxides and crossings proccesionals principally, worked in silver or copper.

Fifteen inscriptions that are gathered in this article do not form a part of a collection independent from the museum, but they are included in two of his principal collections, archaeology and Spanish silverwork. There is claimed the reading and critical edition of his texts, attending to the recent trends of the epigraphic investigation that conceive the inscription as a way of communication of advertising character in which they control three elements - author, rogatario and addressee - organized in two phases, actio and conscriptio epigráficas. As for the typology of epigraphs established by some authors in analogy with the documentary science and, in relation to the most frequent groups in the epigraphics collections, we will differ between epitaphia, suscriptiones, invocationes and donationes.

Keywords: Inscription, Middle Age, Diocesanum Museum Regina Coeli, estela, epitaph, píxide, cross processional. 
El Museo Diocesano se encuentra ubicado en el antiguo convento de frailes dominicos "Regina Coeli", en el conjunto histórico de Santillana del Mar. Su fundación se remonta al año 1592 bajo la iniciativa de Alonso de Velarde, señor del Palacio de las Arenas, pasando posteriormente a depender del Duque del Infantado y trasladándose a su emplazamiento actual ${ }^{1}$. Comenzó a levantarse en 1612 y la iglesia se consagró en 1648. El inmueble fue ampliándose con reformas y añadidos hasta que en 1835 lo desalojó la orden dominicana y pasó a ser ocupado por la comunidad de monjas clarisas del convento santanderino de San Francisco. A finales de los sesenta, se creó el Museo Diocesano cuya finalidad es conservar, estudiar y divulgar el patrimonio artístico religioso de la Diócesis. Sus dependencias albergan también el Archivo Diocesano Documental que recoge microfilmados los pergaminos y libros de las 617 parroquias de la Diócesis, entre los que se encuentran libros de fábrica, apeos, diezmos, registros sacramentales, tazmías, cofradías, etc., además de fondos de documentación civil y religiosa que se custodiaban en los respectivos archivos parroquiales ${ }^{2}$. El Archivo dispone de su propio taller de restauración documental. El Museo Diocesano desempeña en la actualidad una importante labor de asesoramiento técnico en materia de conservación de patrimonio artístico, a través, entre otros mecanismos, de su Taller de Restauración de pinturas murales, retablos e imaginería religiosa ${ }^{3}$.

Este espacio museográfico conserva un porcentaje exiguo de epígrafes de cronología medieval, aunque superior incluso al del Museo de Prehistoria y Arqueología de Cantabria, principal "contenedor" arqueológico de la región, que cuenta entre sus fondos con el epitafio de la lauda sepulcral de Aldea de Ebro, algunas estelas funerarias epigráficas procedentes de contextos de necrópolis como Espinilla y Retortillo principalmente, y un fragmento de inscripción con caracteres góticos escrita en romance procedente del antiguo convento de San Francisco y publicada por Vega de la Torre en su compilación de la epigrafía romana, medieval y moderna de este mu$\mathrm{Seo}^{4}$. La reciente catalogación de las estelas funerarias medievales del Museo Diocesano "Regina Coeli", ha incluido la epigrafía y onomástica de tres inscripciones recogidas en este trabajo: la estela de Monegro y los fragmentos lapidarios de Sierra de Ibio y Caviedes 5 .

El conjunto epigráfico del MDC abarca cronológicamente la Alta y la Baja Edad Media, con ejemplares comprendidos entre los siglos IX y XV.. La estela de Monegro, los epitafios de Sierra de Ibio y Caviedes y la suscriptio de Antero, en la celosía de Enterrías, aunque carecen de fecha, bien porque no se consignó, bien porque se ha perdido por su estado de conservación, se sitúan en los siglos altomedievales, a juzgar por sus caracteres escriturarios, morfológicos, funcionalidad y contexto. Por su parte, la epigrafía de los objetos litúrgicos metálicos de la colección se situaría entre los siglos XIII y XV, principalmente durante la segunda mitad de la decimoquinta centuria, valorando en este caso además de los criterios anteriores, sus características técnicas, estilísticas, estéticas y materiales. Atendiendo a sus caracteres externos, se han empleado la escritura visigótica para las inscripciones en soportes pétreos, la carolina para los monogramas de Jesucristo en las cruces procesionales de Piasca y Hoz de Abiada y la gótica minúscula para las epigrafías bajomedievales. Los textos aparecen escritos en latín y romance. Aunque el romance se generaliza a

J. GÓMEZ MARTÍNEZ, Regina Coeli (Santillana, 1592-1835): Arte y patronazgo en la primera fundación dominicana de Cantabria, Santander, 1993, pp. 23-28.

2 E. CAMPUZANO RUIZ, Museo Diocesano Regina Coeli, Santander, 1990.

F. ZAMANILLO PERAL, Museo Diocesano Regina Coeli, Santander, 1976, pp. 5-6.

J. R. VEGA DE LA TORRE, “Epigrafía del Museo de Santander”, Sautuola, 1, 1975 pp. 216-244.

R. BOHIGAS ROLDÁN y E. CAMPUZANO RUIZ, "La colección de estelas del Museo Diocesano Regina Coeli de Santillana del Mar", actas del VII Congreso Internacional de Estelas Funerarias: Santander, 24-26 de octubre de 2002, vol. 2, 2004, pp. 587-610. 
partir del siglo XIII, la mayor solemnidad que otorga el uso del latín hace que muchos programas epigráficos de los siglos finales continúen empleándolo, especialmente en epitafios, inscripciones explicativas e invocationes, asociadas a objetos litúrgicos mobiliares ${ }^{6}$.

Como todo documento epigráfico e histórico, al estar fuera de contexto, pierde su sentido y funcionalidad, que deberemos rastrear atendiendo al mensaje epigráfico y su contenido, además de la información conservada respecto a su originario emplazamiento en la fábrica del inmueble para el que fue concebido. No obstante, su depósito en museos permite disponer de exhaustivas catalogaciones que permiten su rastreo y contextualización cronocultural ${ }^{7}$. Las fuentes documentales, en especial, en los siglos bajomedievales, aportan informaciones valiosas para la adscripción cronológica de muchas piezas de orfebrería, en especial actas municipales y libros de fábrica que recogen el nombre de los orfebres, centros de producción y funcionamiento de los talleres de los principales centros plateros ${ }^{8}$. Teniendo en cuenta que la publicidad, la perdurabilidad y la solemnidad son algunas de sus principales características, una inscripción no se puede concebir sin su contexto, pues resta información valiosa sobre su origen, funcionalidad, autoría, destinatarios, etc. En cuanto a sus caracteres internos y formulario, de las quince inscripciones catalogadas, tres son inscripciones funerarias (epitaphia), una suscriptio, dos invocationes monogramáticas sobre cruces procesionales y sendas invocationes en objetos de plata. . La epigrafía medieval refleja la mentalidad, las costumbres y la idiosincrasia de la sociedad que la produjo. Es en la mayoría de los casos, en especial durante la Alta Edad Media, un instrumento propagandístico eficaz en manos del clero, principal estamento dinamizador de la cultura de la época. En los siglos bajomedievales, la nobleza y la alta burguesía se erigen en clientes y promotores importantes de la actividad artística y como no, de los programas epigráficos que acompañan la obra de arte 9 .

Como todo medio de comunicación publicitario, la epigrafía medieval presenta un autor, un destinatario y un rogatario del mensaje epigráfico. El autor es el promotor intelectual y la persona que encarga el epígrafe. Por lo general, es un alto cargo eclesiástico, obispo o abad quién se erige en comanditario y por medio de un contrato establece las clausulas a las que deberá ceñirse el rogatario antes y durante la ejecución del programa epigráfico del monumento en cuestión. Junto al destinatario, el autor moral constituye la actio epigráfica o voluntad del autor de perpetuar el

$6 \quad$ M. PÉREZ GONZÁLEZ, "Las inscripciones medievales latinas de la provincia de Zamora. Estudio lingüístico", Minerva: revista de filología clásica, 12, 1998, p. 134. Según este autor, pese a la generalización del uso del romance por razones lingüísticas a partir de la segunda mitad del siglo XIII, se continuará usando el latín en algunas inscripciones de los siglos XIV y XV, por la relevancia de los personajes y hechos registrados en las mismas, que obliga a utilizar materiales costosos y técnicas complejas.

7 Aunque no son frecuentes las catalogaciones de inscripciones medievales de museos recogidas en artículos y publicaciones, como lo pueden ser la de inscripciones romanas o la de otros documentos arqueológicos, lo cierto es que en las últimas dos décadas han proliferado algunos trabajos aislados en los que se inventarían las colecciones epigráficas de espacios museográficos de nuestro país. M. ESCORTELL PONSODA, Catálogo de heráldica y epigrafía medieval y moderna del Museo Arqueológico de Oviedo, Oviedo, 1981. G. S. KURTZ SHAEFER y C. DOMÍNGUEZ DE LA CONCHA, "Epigrafía medieval y moderna del Museo Arqueológico Provincial de Badajoz", Revista de Estudios Extremeños, 52, (1996), pp. 497-529. P. RODRÍGUEZ SUAREZ y M. VÁZQUEZ BERTOMÉU, "De epigrafía medieval lucense: la colección del Museo Provincial de Lugo, Boletín do Museo Provincial de Lugo, 12, (2005), pp. 109-122.

8 R. MARTÍN VAQUERO, “Contribución al estudio de la platería medieval alavesa”, en Revisión del arte medieval en Euskal Herría. Cuad. Secc. Artes Plást. Monum., 15 (1996), pp. 521-522.

9 J. SANTIAGO FERNÁNDEZ, "Las inscripciones medievales castellano-leonesas: documentos al servicio del poder político y religioso", I Jornadas sobre Documentación jurídico-administrativa, económico-financiera y judicial del reino castellano-leonés (siglos X-XIII), Madrid, 2002, p. 113. 
mensaje epigráfico. Si el autor no aparece con frecuencia en la inscripción, más extraña es la consignación del destinatario a quién en la mayoría de los casos se alude de forma genérica, ya sea por medio de una llamada a la oración en segunda persona, como ocurre en los epitafios, o, con un apóstrofe al lector en segunda persona ${ }^{10}$.

El rogatario de una inscripción es el autor material de la misma, es la persona que ejecuta la fase de incisión o esculpido del texto epigráfico y es el responsable de la conscriptio o materialización del mensaje epigráfico que tiene lugar en los scriptoria o talleres epigráficos asociados a importantes centros monásticos, que proyectaban su actividad más allá incluso de su jurisdicción eclesiástica y que tenían en los propios monjes de la comunidad, encargados del copiado e ilustración de códices, a sus lapicidas o scriptores de los mensajes doctrinales. En muchos casos el artesano encargado de esculpir y labrar un relieve, es el encargado también de preparar el espejo epigráfico y grabar el texto con martillo y cincel. En inscripciones solemnes y monumentales, asociadas a importantes miembros del clero y de la nobleza en destacados centros religiosos, es probable que se hayan seguido de forma exhaustiva las tres fases de ejecución material del epígrafe que algunos autores han defendido: minuta, ordinatio e incissio ${ }^{11}$. En lo que respecta a la colección epigráfica del Museo Diocesano "Regina Coeli", es normal que se hayan seguido las tres fases en los objetos litúrgicos metálicos dada su mayor perfección técnica y estilística, su avanzada cronología y su destino litúrgico. Se trata de piezas que en la mayoría de los casos responden a donaciones de particulares que entre los siglos XIII y XV, establecían vínculos de patrocinio con las parroquias en las que elegían ser sepultados tras su muerte, persiguiendo el recuerdo, la oración y la permanencia de su alma. Con estas donaciones o fundación de capillas perpetuaban su vínculo con la Iglesia y reforzaban su posición social ${ }^{12}$. En el caso de las estelas funerarias y fragmentos lapidarios, es casi seguro se obviaran las fases del borrador y la ordinatio y se pasara directamente a la ejecución material del texto, como se puede constatar por lo irregular del trazado de los caracteres que varían en módulo, altura, surco y distancia entre letras, propio de la ausencia de regla y de la espontaneidad característica de la cultura epigráfica rural de los primeros siglos medievales.

\section{COLECCIÓN EPIGRÁFICA}

\section{1.- Epitaphia}

Las inscripciones funerarias (epitaphia) son las más abundantes en las colecciones epigráficas. Pueden distinguirse, por un lado, epitafios necrológicos, cuando sólo recogen la muerte de una persona con el verbo notificativo obiit en la mayoría de los casos y con un formulismo caracterizado por su brevedad y rigidez. Antes o después de la notificación casi siempre se consigna la fecha, completa o sólo el año del óbito, y la intitulación o nombre del difunto. Por su parte, los epitafios sepulcrales indican que allí están depositados los restos de la persona empleando un formulario más amplio y variado. Suelen comenzar con el verbo notificativo hic requiescit o hic iacet, seguido de la intitulación, que recoge el nombre del difunto, acompañado de algunos

10 V. GARÍA LOBO y E. MARTÍN LÓPEZ, "La escritura publicitaria en la Edad Media: su funcionalidad, Estudios humanísticos: Geografia, Historia y Arte, 18, 1996, p. 131.

11 G. SUSINI, Il lapicida romano: introduzione all' epigrafía latina, Roma, 1966.

12 A. PEÑA FERNÁNDEZ, "Nueva lectura del epitafio sepulcral de Juan Sánchez de Bustamante (1392)", Sautuola, XIV (2008), pp. 332-335. 
atributos, siendo el más frecuente famulus, famulo o famula dei. En ocasiones pueden añadirse epítetos que ensalzan las virtudes del sepultado y a continuación una exposición de sus actos en vida para rememorarle y orar por su alma ${ }^{13}$. El formulario de cierre de estos epitafios suele recoger expresiones como orate pro eo o requiescat in pace, pidiendo una oración por su eterno descanso. En ocasiones, suele recurrirse en este tipo de epitafios al verso leonino para conseguir por medio del estilo versificado un lenguaje más cuidado que despierte más interés en el lector y de paso realce el prestigio social de la persona enterrada ${ }^{14}$. Su evolución en los estilos románico y gótico supone un enriquecimiento de sus programas iconográficos y epigráficos que se hace más patente en los siglos XIV y XV como consecuencia de las condiciones impuestas en las clausulas de los contratos por los clientes de las mismas que ahora son principalmente miembros del estamento nobiliar a diferencia de los siglos altomedievales donde los comanditarios eran los altos cargos eclesiásticos ${ }^{15}$.

Epitafios necrológicos y sepulcrales suelen aparecer grabados o esculpidos en laudas sepulcrales, cajas de sarcófagos y empotrados en las paredes del edificio formando parte de lápidas funerarias que estarían asociadas a enterramientos próximos y cuya ubicación respondería a una lectura más cómoda. Sin embargo, la proliferación de letreros epigráficos será más frecuente en la epigrafía y escultura funeraria de los siglos XIV y XIV formando parte del programa iconográfico de muchos monumentos funerarios ${ }^{16}$.

Los fragmentos de inscripciones funerarias de Caviedes y Sierra de Ibio pertenecen probablemente a tapaderas de sarcófago altomedievales que, en el primer caso, habría sido reutilizada como material constructivo en la fábrica del templo, mientras que el hallazgo de la segunda, se produjo en el contexto de una necrópolis de tumbas de lajas. En la ermita de San Pedro de Caviedes, se localizó durante el transcurso de unos trabajos de desescombro previos a su restauración, un fragmento de losa sepulcral reutilizado en el muro meridional de la fábrica. Contenía en su anverso un epitafio incompleto en caracteres visigóticos con el siguiente formulario: invocatio monogramática en cruz, notificatio, intitulatio y parte inicial de una datatio ${ }^{17}$. En el epitafio de Sierra de Ibio, Bohigas Roldán en base a dataciones radiocarbónicas efectuadas en algunas necrópolis de tumbas de lajas, paralelos epigráficos y morfológicos, sitúa su ejecución entre los siglos VII y IX ${ }^{18}$.

Sin embargo, un soporte muy frecuente de las epitafios son las estelas funerarias, cuya función original habría que poner en relación con la señalización de los enterramientos en cualquiera de las modalidades documentadas en las necrópolis, es decir, tumbas de lajas, enterramientos en roca o sarcófagos, estos últimos probablemente restringidos a los estamentos privilegiados

13 V, GARCÍA LOBO y E, MARTÍN LÓOPEZ, De epigrafía medieval: introducción y álbum, León, 1995, p. 39.

14 J. DEL HOYO y P. KURT RETTSCHLAG, "Carmen medieval en la iglesia de Santa María, en Tábara (Zamora)", Faventia, 29, 2007, pp. 71-77.

15 J. SANTIAGO FERNÁNDEZ, "La epigrafía bajomedieval en Castilla", II Jornadas científicas sobre documentación de la Corona de Castilla. Siglos XIII-XV, Madrid, 2003, p. 249.

16 J. SANTIAGO FERNÁNDEZ, "El programa epigráfico del monumento sepulcral de Martín Vázquez de Arce (el doncel de Sigüenza), Cuadernos de investigación histórica, 23, 2006.

17 VV. AA., "La ermita de San Pedro de Caviedes", Clavis: boletín del Museo Diocesano de Santillana del Mar, 1, 1996, pp. 109-140.

18 R. BOHIGAS ROLDÁN y E. CAMPUZANO RUIZ, "La colección de estelas del Museo Diocesano Regina Coeli de Santillana del Mar, Cantabria", Actas del VII Congreso Internacional de Estelas Funerarias: Santander 2426 octubre 2002, vol. 2, Santander, 2004, p. 601. 
de la sociedad medieval y menos frecuentes en el contexto de necrópolis ${ }^{19}$. Aunque su origen y funcionalidad se desconocen, por su morfología y estereometría antropomorfa, parece evidente su relación directa con el mundo funerario. Aunque la mayor parte de las estelas conservadas son anepígraficas, algunas poseen inscripciones caracterizadas por su brevedad, pudiendo clasificarse según algunos autores entre las que recogen onomástica y las que presentan letras sueltas grabadas $^{20}$. No presentan ninguna estructura de formulario. Su escritura presenta las características habituales de la visigótica mayúscula con escasa presencia de unciales y minúsculas agrandadas, aunque la inseguridad de su ductus, la escasa regularidad en el módulo de sus caracteres, la ausencia de líneas guía y de pautado, junto a la disposición del texto sin espejo epigráfico, hace segura la ausencia de minuta y ordinatio, habiéndose grabado directamente el texto sobre el so-

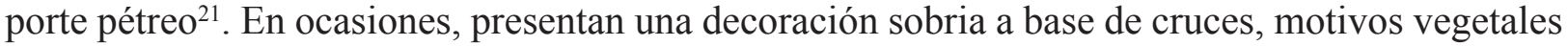
y astrales o esquematizaciones humanas por una o ambas caras ${ }^{22}$. La conocida como estela de Monegro presenta una representación humana esquematizada con trazo inciso y rehundido y una inscripción en el anverso, organizada en dos renglones, que recoge simplemente el nombre del difunto como suele ser habitual en este tipo de epígrafes funerarios ${ }^{23}$. Debe entenderse a falta de fórmula funeraria, como "aquí yace Gegitus". En su reverso, se grabó un motivo cruciforme que no encuentra paralelos entre las tipologías de cruces conocidas. Se presentan dos variantes de lectura según se interpreten las piernas del antropomorfo como una doble L o sin esa función gráfica:

\section{GE / GLALLUR \\ GE / GITUS}

García Alonso atendiendo a cuestiones formales, epigráficas y estilísticas, sitúa el epitafio de Gegitus entre los siglos XI y XII, aunque puntualiza la ausencia de antropónimos en nominativo, la singularidad del motivo decorativo de esta estela discoidea y la referencia simbólica al difunto con la representación de un antropomorfo ${ }^{24}$.

\section{2.- Invocationes}

Este grupo de inscripciones suele ser también abundante en los corpus o colecciones epigráficas medievales y se caracteriza por recoger una oración o deseo piadoso pidiendo protección. Pueden ser monogramáticas, cuando se consigna una simple cruz o el monograma de Jesucristo o verbal. El uso de fórmulas diplomáticas de documentos jurídicos en muchas de estas inscrip-

19 R. BOHIGAS ROLDÁN, "La organización social del espacio a través de la arqueología medieval: veinte años de investigaciones", Actas del I Encuentro de Historia de Cantabria, Santander, 1999, p.

20 C. MARTÍN GUTIÉRREZ, Estelas funerarias medievales de Cantabria, Santander, 2000, p. 241.

21 C. MARTÍN GUTIÉRREZ, "Las estelas funerarias de Cantabria: su epigrafía", Codex aquilarensis: cuadernos de investigación del Monasterio de Santa María la Real, 9, 1993, pp.7-24.

22 C. MARTÍN GUTIÉRREZ, "Esquematizaciones humanas en las estelas altomedievales de Cantabria", Cuadernos de etnología y etnografía de Navarra, 66, 1995, pp. 403-409.

23 J. R. VEGA DE LA TORRE, “Aspectos onomásticos y epigráficos de las estelas altomedievales cántabras”, Zainak: Cuadernos de antropología-etnografía, 10, 1994, pp. 297-316.

24 M. GARCÍA ALONSO, "La estela de Monegro (Campo de Yuso): un nuevo antropomorfo en las manifestaciones funerarias medievales de Cantabria", Actas del VII Congreso Internacional de Estelas Funerarias: Santander 24-26 de octubre de 2002, 2 (2004), pp. 479-481. 
ciones, como en otras de distinta tipología, ya ha sido apuntado por Favreau, García Lobo, Fernández Flórez y Domínguez Sánchez, entre otros autores ${ }^{25}$. Suelen aparecer en distintos soportes o lugares del templo. Es habitual su presencia en pequeños objetos mobiliares que componen el ajuar litúrgico del templo cristiano. Es el caso del monograma IHS de las cruces de Piasca y Hoz de Abiada. Muchas veces responden a la fórmula de una salutación angélica: ave maria o ave maria gratia plena. En muchos casos, se trata de textos un tanto ambiguos que pueden interpretarse también como explanationes o inscripciones que suelen acompañar con carácter explicativo a algunas imágenes iconográficas de tipo escultórico o pictórico. Su principal función es la de aclarar e ilustrar los programas iconográficos identificando en muchos casos a los personajes que aparecen o la función del objeto artístico. Algunos autores han destacado su carácter pedagógico, en cuanto que la inscripción que acompaña la obra de arte es la traducción de lo que el autor quiere expresar a través del programa iconográfico ${ }^{26}$. La aparición de inscripciones de esta naturaleza en el arte mueble litúrgico del templo cristiano comienza a ser frecuente en los siglos XIV y XV, en especial en obras de orfebrería y platería de carácter religioso como cálices, píxides y cruces procesionales. Por lo general, se trata de pasajes bíblicos extraídos de las Sagradas Escrituras que pretenden reforzar la fe cristiana y al mismo tiempo ilustrar sobre la funcionalidad y el contenido del objeto litúrgico, presentándose como invocationes más que como explanationes.

\section{3.- Suscriptiones}

Bajo esta denominación se incluyen todas aquellas inscripciones que recogen el nombre del autor material de una obra de arte. Suelen presentar simplemente su nombre en nominativo o junto al verbo notificativo, acompañado del pronombre personal en primera persona, dependiendo si el texto está redactado en latín o romance: $N$. me fecit o $N$. me fizo. Si la firma corresponde al artífice de la inscripción, nos encontramos entonces ante una suscripción del rogatario. En estos casos, la notificación puede ser más específica optando por fórmulas del tipo notuit o scripsit. Nos encontraríamos ante el responsable del programa epigráfico de la obra de arte o del conjunto escultórico-arquitectónico, lapicida, ordinator, incissor o sculptor, que habría grabado las letras en el soporte, previo encargo del comanditario o promotor del mensaje epigráfico y atendiendo a las directrices de un taller -scriptorium epigráfico- que, bajo la coordinación del magister, supervisaría todas las fases de su materialización -minuta, ordinatio e incissio- y velaría por la conservación y custodia de los instrumentos escriturarios ${ }^{27}$.

En ocasiones, junto a la intitulatio que nunca faltará y a la notificatio, pueden aparecer circunstancialmente otras fórmulas, como el uso de algún atributo para referirse a la condición del artífice: magister, operarius, sculptor, etc. y en algunas ocasiones la data. La epigrafía medieval de Cantabria nos ha proporcionado escasos testimonios de rogatarios o artífices materiales de las inscripciones y en muchos casos de los relieves escultóricos a los que acompañan. Muchas veces se desconoce si es el autor del epígrafe, de la obra escultórica o de la fábrica del edificio, de alguna reforma o ampliación del templo, al no consignarse un verbo especifico sobre su actividad profe-

25 S. DOMÍNGUEZ SÁNCHEZ, "Las fórmulas diplomáticas latinas en epigrafía”, Documenta \& Instrumenta, 6 (2008), pp. 180-182.

26 V. GARCÍA LOBO, "La inscripción y la obra de arte. Sus relaciones", Promonumenta: revista de la Asociación de Amigos del Patrimonio Cultural de León, V (2001), pp. 6-10.

27 V. GARCÍA LOBO, "La epigrafía medieval. Cuestiones de método", en Centenario de la Cátedra de Epigrafía y Numismática Universidad Complutense de Madrid 1900-01-2000-01, Madrid, 2001, pp. 94-95. 
sional y papel desempeñado en una parte o en toda la obra. Es probable que en muchos de estos casos, el nombre al que alude el epígrafe sea el del autor moral de las inscripciones, comitentes que se erigen en creadores del mensaje y financiadores de las obras de arte en las que estos se insertan ${ }^{28}$. Pueden ser los casos del maestro de obra Covaterio en Piasca, Covaterio operis magistro, Pedro Quintana en Yermo: Petro Quintana me fecit ..., Sancho en la pila bautismal de La Costana: Sancius me fecit, Mateo en Silió: Matei memento, Fernando ? en Ojedo: ... ado me fizo, Juan Fernández de Aniezo y Toribio de Cambarco en la segunda parte de la inscripción de Piasca de 1439 o Félix en la consecratio de Pesquera, en la que no queda claro si se trata de la persona que encarga o ejecuta el altar con el epígrafe de consagración o simplemente se limita a grabar el texto. Lo mismo puede decirse de Miguel en la inscripción de consagración de Somballe, donde el verbo fecit crea cierta ambigüedad a la hora de referirse solo al scriptor o al artesano que llevó a cabo alguna obra en una parte del edificio: Michaelis fecit. Es una fórmula demasiado genérica. En las suscriptiones de rogatarios el verbo fecit equivale a scripsit o notuit ${ }^{29}$.

El Antero de la celosía de Enterrías podría ser el primer maestro que trabaja en Cantabria y deja firmada su obra como autor material entre los siglos IX y X, a tenor de las características estilísticas de la pieza y su proximidad cronológica al arte prerrománico asturiano y al arte de repoblación, en el que este tipo de obras escultóricas es bastante frecuente. Si la celosía ocupa su emplazamiento originario como parte de la fábrica de esta iglesia, no es descartable que nos encontremos ante el magister responsable de la edificación del templo entre los siglos IX y X: Anterus me fecit. Algunos autores han apuntado a un origen prerromano para este onomástico al no aparecer su nombre en los cartularios medievales ${ }^{30}$.

Las suscripciones guardan una relación estrecha con la obra de arte, no entendiéndose muchas veces la una sin la otra. Frente a la opinión generalizada sobre el anonimato de los primeros artistas y artesanos medievales que prefieren permanecer en un segundo plano por considerar irrespetuosa la aparición de su nombre junto a la obra sagrada, las suscriptiones reflejan una reivindicación del oficio artesanal para dejar constancia de su nombre y que éste perdure en el tiempo. Sin embargo, su proporción es reducida frente a otro tipo de inscripciones diplomáticas como los epitaphia, las consecrationes o los monumenta ${ }^{31}$.

\section{4.- Donationes}

Este tipo de epígrafes recogen la noticia de la donación de un edificio o de un objeto de culto litúrgico -instrumenta- a una institución o individuo ${ }^{32}$. No suelen ser abundantes en las colecciones epigráficas. Por lo general, presentan un formulario en el que no suele faltar el nombre del donatario. Los verbos notificativos más empleados son los latinos offere y dare. En romance suelen aparecer fórmulas notificativas del tipo dono y lego, en primera persona. Es frecuente que

28 J. SANTIAGO FERNÁNDEZ, La epigrafía latina medieval en los condados catalanes (815-circ. 1150), Madrid, 2003, pp.

29 A, PEÑA FERNÁNDEZ, “Autores, rogatarios y destinatarios de las inscripciones medievales”, en Homenaje a J. A. García de Cortazar (en prensa).

30 E. CAMPUZANO RUIZ, “Celosías prerrománicas en Liébana”, Clavis: boletín del Museo Diocesano de Santillana del Mar, 2 (1998), pp. 101-102.

31 V. GARCIA LOBO y E. MARTÍN LÓPEZ, "Las suscriptiones: relación entre el epígrafe y la obra de arte", en Actes du Colloque: Épigraphie et Iconographie 1995, Poitiers, 1996, pp. 75-99.

32 V. GARCIA LOBO, De epigrafía medieval ... pp. 35-36. 
se consigne la fecha, en ocasiones completa, más habitual en la epigrafía gótica de instrumenta. En palabras de Santiago Fernández, este tipo de inscripciones "pretenden rendir honor al donante, pero al mismo tiempo se convierten en auténticas marcas de propiedad que, en muchas ocasiones, podían reemplazar con éxito al documento emitido por el oferente, dado que en ellas normalmente se consignaban los nombres del donatario como del destinatario"33.

Este tipo de epígrafes son análogos a las roborationes, aunque a diferencia de estas, en las que se recoge el nombre del comanditario de una obra artística, en las donationes, su notificación se formula al modo de los documentos, con fórmulas como iussit fieri, fecit fieri, fis facere, etc. En el caso de la custodia de Castro Urdiales, una de las piezas más relevantes de la platería gótica castellana, además del nombre del donante, se consigna el del maestro platero que la realizó, Martín Follou. Por tanto, nos encontraríamos ante una donatio, que contiene implícita una suscriptio. Si además de labrar la custodia y su iconografía, Martín Follou se encargó también de grabar a buril los caracteres escriturarios que contornean la arqueta eucarística, se trataría de una suscriptio de rogatario, es decir, la firma del autor material de la inscripción ${ }^{34}$.

\section{APÉNDICE EPIGRÁFICO}

1.

\section{S. X - XIII}

Epitaphium de Gegitus

A. MONEGRO, CAMPOO SE YUSO, estela funeraria discoide, escritura visigótica minúscula. Buena conservación.

PUBL.: M. GARCIA ALONSO, "La estela medieval discoidea de Monegro (Campoo de Yuso)", Trabajos de Arqueología en Cantabria, 5, pp. 99-102. "La estela de Monegro (Campoo de Yuso): un nuevo antropomorfo en las manifestaciones funerarias medievales de Cantabria", Actas del VII Congreso Internacional de Estelas Funerarias: Santander 24-26 de octubre de 2002, 2 (2004), pp. 473-488.

GE

GITUS

Gegitus

MDC no inv. 1176, Arqueología

Lám. 1

33 J. SANTIAGO FERNÁNDEZ, Epigrafía medieval ...

34 A. BARRÓN GARCÍA, "Platería hispano flamenca vizcaína: Martín Folloy y Pedro Martínez de Otaza", San Eloy 2004. La calidad de cada pieza de plata quedaba plasmada con tres marcas diferenciadas, la del maestro platero, la de fiel contraste y la de localidad. La marca del platero, recoge su nombre y ocasionalmente, su apellido abreviado o mediante símbolos. Una vez acreditada su profesión por el Gremio de plateros, podía marcar sus obras con un sello o punzón personal que lo identificaba de otros plateros. La marca de fiel contraste, consistía en el visto bueno de un maestro designado por el gremio de plateros, para comprobar la calidad de la plata utilizada y si esta se ajustaba a la legalidad vigente, para lo cual estampaba su marca a modo de garantía. Por último, la marca de localidad consignaba la pertenencia del platero y su obra a una región determinada. 
S. IX ex. - XII inc.

Epitaphium necrologicum de Juliano

A. ERMITA DE SAN PEDRO DE CAVIEDES, Valdáliga, fragmento de inscripción funeraria, apareció durante el transcurso de las obras de restauración como material reutilizado en el ángulo suroeste. Letra visigótica mayúscula. Mal estado de conservación.

PUBL.: AA. VV.: La ermita de San Pedro (Caviedes, Valdáliga, Cantabria), Santander: I. E. S. Valle del Saja, 1997, pp. 39-42.

+ OBIT ULIANO

[...] CIE IN ER

(cruz) Falleció Juliano ... en la era

MDC $n^{\circ}$ inv. 1177, Arqueología.

Lám. 2

3.

S. VII - IX

Epitaphium de Pennous

A.FINCA “LA CASUCA”, SIERRA DE IBIO, MAZCUERRAS, fragmento de lápida funeraria hallada en el contexto de una necrópolis de tumbas de lajas. Escritura visigótica. Mal estado de conservación.

PUBL.: R. BOHIGAS ROLDÁN y E. CAMPUZANO RUIZ, "La colección de estelas del Museo Diocesano Regina Coeli de Santillana del Mar", actas del VII Congreso Internacional de Estelas Funerarias: Santander, 24-26 de octubre de 2002, vol. 2, 2004, pp. 599-601.

+ PENNOUS

(cruz) Pennous

MDC $n^{\circ}$ inv. 1178, Arqueología.

Lám. 3

\section{4.}

Siglos IX - X

Suscriptio de Antero como artífice de una celosía.

A.ENTERRÍAS, VEGA DE LIÉBANA, iglesia parroquial. La existente en el Museo Diocesano es copia. La original estuvo intestada en el basamento del altar de la iglesia parroquial. Dimensiones: 69 x 59 cms. Letra visigótica mayúscula. Conservación deficiente.

PUBL.: E. CAMPUZANO RUIZ, "Celosías prerrománicas en Liébana”, Clavis: boletín del Museo Diocesano de Santillana del Mar, 2 (1998), pp. 101-102.

ANTERUS ME FECIT

Antero me hizo

MDC $n^{\circ}$ inv. 1178, Arqueología.

Lám. 4 


\section{5.}

\section{Siglo XV}

Invocatio de un hostiario o cáliz de Quintana de Soba.

A.QUINTANA DE SOBA, hostiario, caracteres góticos minúsculos contorneando la copa cilíndrica. En el envés del pie se grabó la marca del platero.

PUBL.: E. CAMPUZANO RUIZ, El Gótico en Cantabria, Santander, 1985, p.495.

HOC EST CORPS DOMINI NRI IHESU

IV(LI $)^{\mathbf{o}}$ LOPES

Este es el cuerpo de Nuestro Señor Jesucristo

Julio López

MDC n ${ }^{\circ}$ inv. 553, Platería española.

Lám. 5

6.

S. XV

Invocatio de una píxide

A.REOCIN DE LOS MOLINOS, VALDEPRADO DEL RÍO, La inscripción discurre alrededor de la caja a modo de friso. Escritura gótica minúscula. No tiene marcas.

PUBL.: E. CAMPUZANO RUIZ, El gótico en Cantabria, Santander, 1985, p.496.

AVE MARIA GRATIA PLENA DOMINUS TECUM BENEDIT

Dios te salve María llena de gracia, el señor te bendiga

MDC no inv. 202, Platería española.

Lám. 6

7.

S. XV

Invocatio de una píxide

A.MATIEZO DE RUESGA, Mismo tipo de escritura que los anteriores. El epígrafe se dispone resaltado alrededor de la caja cilíndrica. No presenta marcas.

PUBL.: E. CAMPUZANO RUIZ, El Gótico en Cantabria, Santander, 1985, p.496.

AVE MARIA GRA PLENA DOMINU

Dios te salve María llena de gracia, el señor

MDC, Platería española. 


\section{8.}

\section{S. XV}

Invocatio de una píxide

A.ALDUESO, SANTIURDE DE REINOSA, La inscripción discurre perimetralmente por la caja. Escritura gótica minúscula. Conserva marca de localidad (Burgos), de fiel contraste (COP), mientras que es ilegible la de platero.

PUBL.: E. CAMPUZANO RUIZ: El Gótico en Cantabria, Santander, 1985, p.496.

AVE MARIA GRATIA PLENA DOMINUS TECUM BENEDIT

Dios te salve María llena de gracia, el señor te bendiga

MDC $n^{\circ}$ inv. 528, Platería española.

Lám. 7

\section{9.}

S. XV

Invocatio de una píxide

A.POLIENTES DE VALDERREDIBLE, la inscripción rodea la caja en caracteres góticos munúsculos. Presenta marca en el envés de la base, marca de localidad (Burgos), marca de fiel contraste y de platero (Arenas).

PUBL.: E. CAMPUZANO RUIZ, El Gótico en Cantabria, Santander, 1985, p.496.

HIC EST CORPUS DOMINE NOSTRI IHESU CHRISTI

COP B. ARENAS

Este es el cuerpo de Nuestro Señor Jesucristo

MDC $\mathrm{n}^{\circ}$ inv. 508, Platería española.

Lám. 8

10.

1466

Donatio de una custodia y suscriptio del platero Martín Follou.

A. SANTA MARÍA DE CASTRO URDIALES, La extensa inscripción en caracteres góticos minúsculos está grabada a cincel y discurre sobre un estrecho campo epigráfico a modo de orla, bajo las escenas iconográficas de la Pasión de las caras laterales del copón. Recoge el nombre del donante, del artífice material, maestro platero que muy probablemente es el rogatario del epígrafe y la fecha de ejecución.

PUBL.: E, CAMPUZANO RUIZ, El Gótico en Cantabria, Santander, 1985, pp. 492-493. BARRÓN GARCÍA, A. (2004): "Platería hispano flamenca bilbaína: Martín Follou y Pedro Martínez de Otaza", Estudios de platería San Eloy 2004, pp. 99-118.

SENDO : MARDOMOS : PERO SAES DE CASTANEDA : CURA : E MARTYN : PERES: DEL CAMPO : LEGO : FISOLA MYN FOLLOU PLATERO ESTA OBRA SE FYSO : EN LA ERA DEL NACIMYENTO DEL SEÑOR DE MYLL E CCCCXVI ANOS

Siendo mayordomos Pedro Sáez de Castañeda y Martín Pérez del Campo dono, la hizo el platero Martín Follou. Esta obra se hizo en la era del nacimiento del señor de 1466. MDC n inv. 810, Platería española. Lám. 9 
11.

S. XIII

Invocatio de la cruz de Piasca.

A.SANTA MARÍA DE PIASCA, La inscripción monogramática aparece en una cartela rectangular sobre la cabeza del Cristo. Escritura carolina mayúscula. Buena conservación.

PUBL.: E. CAMPUZANO RUIZ, El Gótico en Cantabria, Santander, 1985, p.485.

IHS

Jesucristo

MDC $\mathrm{n}^{\circ}$ inv. 602, Arqueología.

Lám. 10

12.

s. XIV

Invocatio en una cruz procesional de cobre.

A.HOZ DE ABIADA, CAMPOO DE SUSO, La inscripción monogramática aparece por encima de la cabeza del Cristo

PUBL.: E. CAMPUZANO RUIZ, El Gótico en Cantabria, Santander, 1985, p.490.

IHS

Jesucristo

MDC nº inv. 390, Arqueología.

Lám. 11

13.

S. XV

Invocatio en una píxide

A.LINARES, PEÑARRUBIA, Letra gótica minúscula en friso epigráfico bordeado por dos impostas de cordón que recorre la caja cilíndrica.

PUBL.: E. CAMPUZANO RUIZ, El Gótico en Cantabria, Santander, 1985, p.496.

AVE MARIA GRATIA PLENA DOMINUS TECUM BENEDIT

Dios te salve María llena de gracia, el señor te bendiga

MDC n ${ }^{\circ}$ inv. 897, Platería española.

Lám. 12 
14.

S. XVI inc.

Invocatio en una píxide

A. SANTA CRUZ DE IGUÑA, La inscripción en caracteres tardogóticos minúsculos ocupa toda la superficie cilíndrica.

PUBL.: E. CAMPUZANO RUIZ, El Gótico en Cantabria, Santander, 1985, p.496.

MATER DEI MEHI EO

Madre de Dios, ven a mí.

MDC $n^{\circ}$ inv. 318, Platería española.

Lám. 13

\section{5.}

\section{S. XV}

Invocatio en una píxide

A. VILLAR DE SOBA, Letra gótica minúscula. Buena conservación.

AVE MARIA + GRA + PRO NO + PECCATORIBU

Dios te salve María llena de gracia, ora por nosotros pecadores

MDC nº inv. 525, Platería española.

16.

S. XV

Invocatio en una cruz de cobre

A. VILLASUSO DE CIEZA, Escritura gótica mayúscula. En la parte donde debería ir INRI, aparece el monograma de Cristo. La S aparece invertida y de la H sólo se grabó la mitad izquierda por falta de espacio. Buena conservación.

PUBL.: E. CAMPUZANO RUIZ, El Gótico en Cantabria, Santander, 1985, p.490.

ISH

Jesucristo

MDC nº inv. 316, Arqueología.

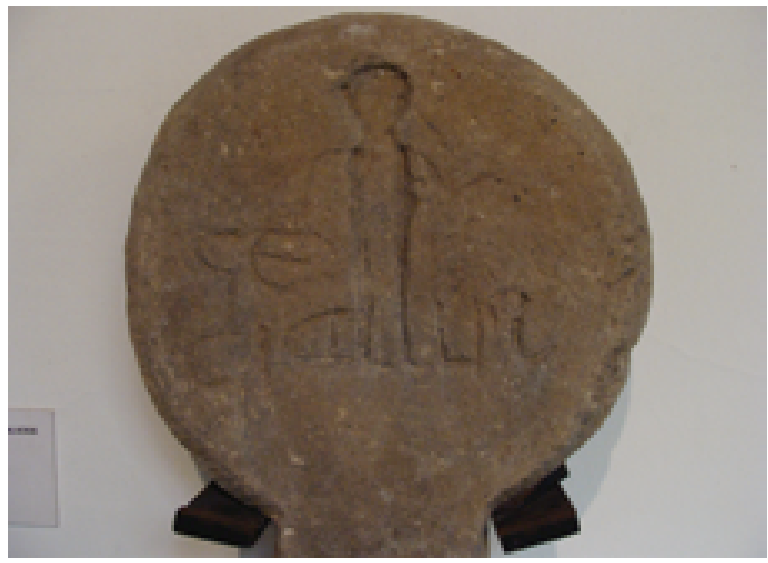

Lám. 1. Epitaphium de Gegitus.

Foto Enrique Campuzano 


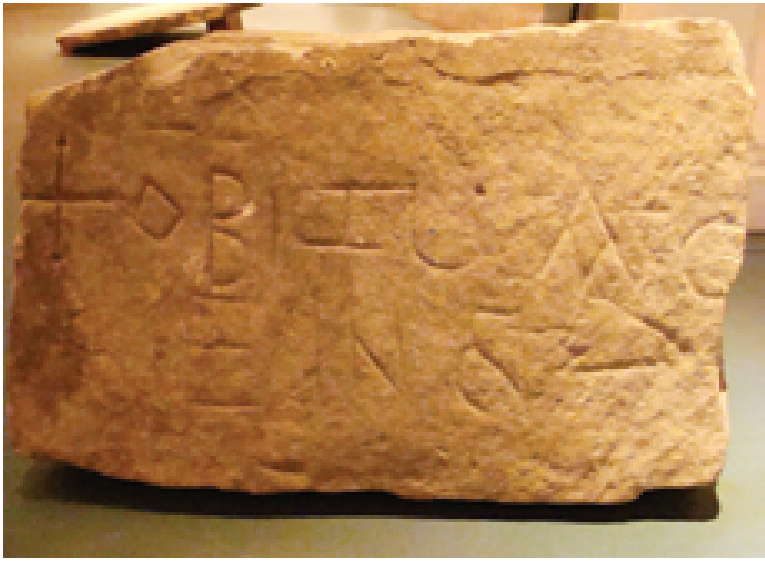

Lám. 2. Epitaphium de Juliano. Foto Enrique Campuzano

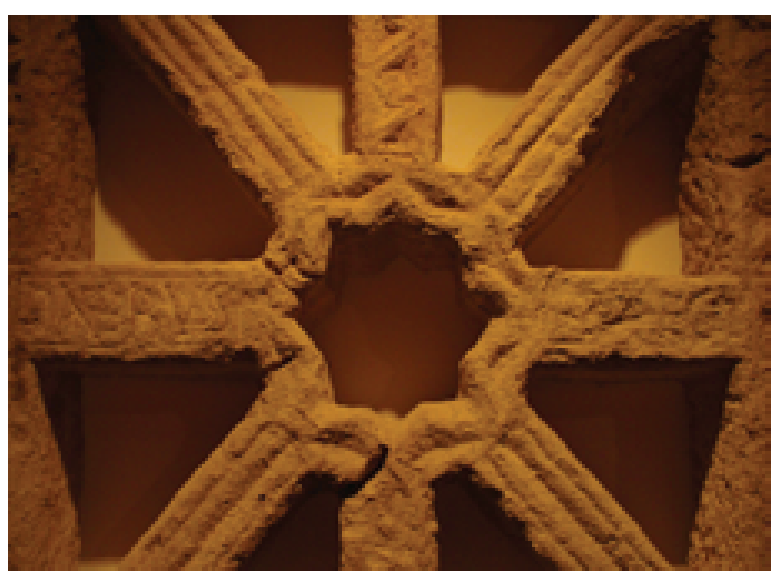

Lám. 4. Suscriptio de Antero. Foto Enrique Campuzano

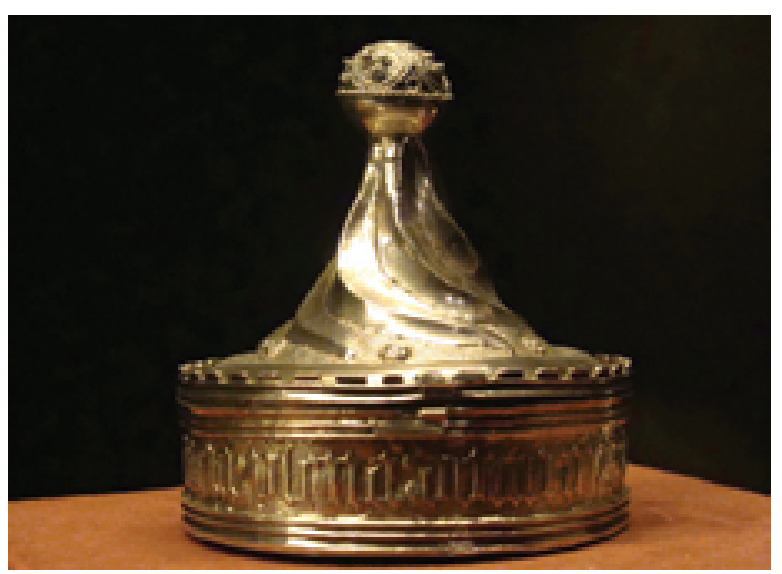

Lám. 6. Invocatio en una píxide de Reocín de los Molinos. Foto Enrique Campuzano

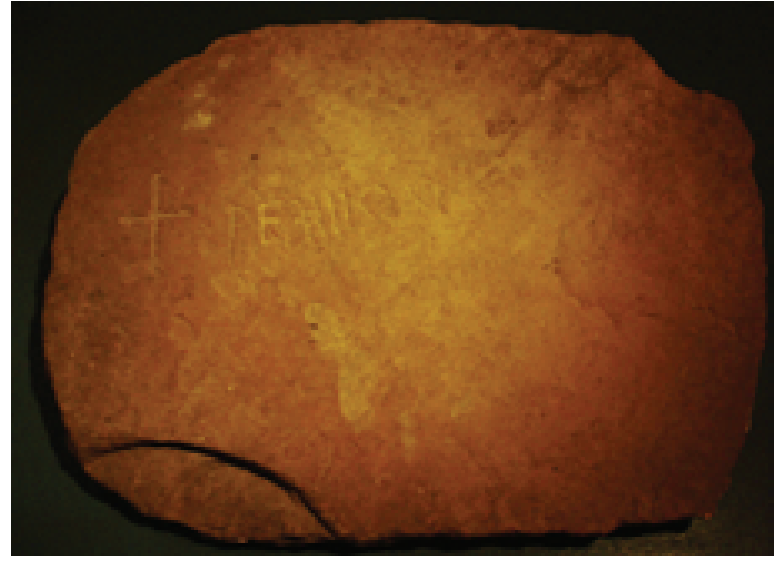

Lám. 3. Epitaphium de Pennous. Foto Enrique Campuzano

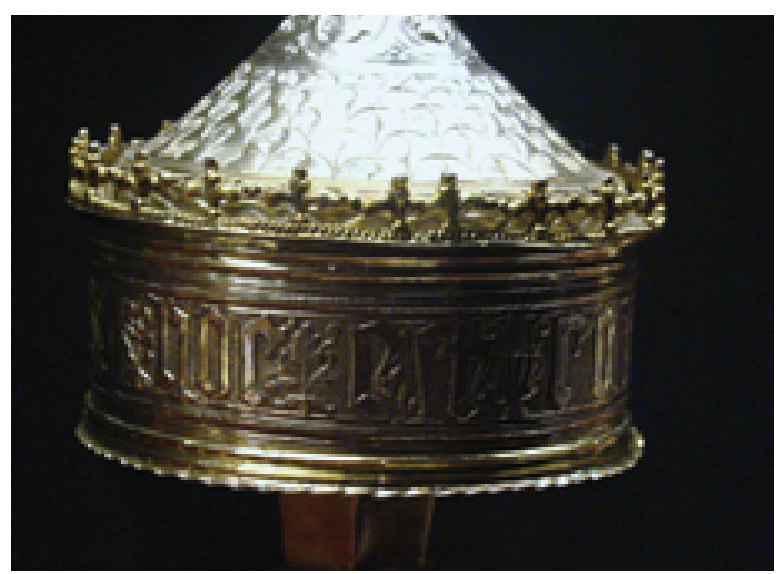

Lám. 5. Invocatio en un cáliz de Quintana de Soba. Foto Enrique Campuzano

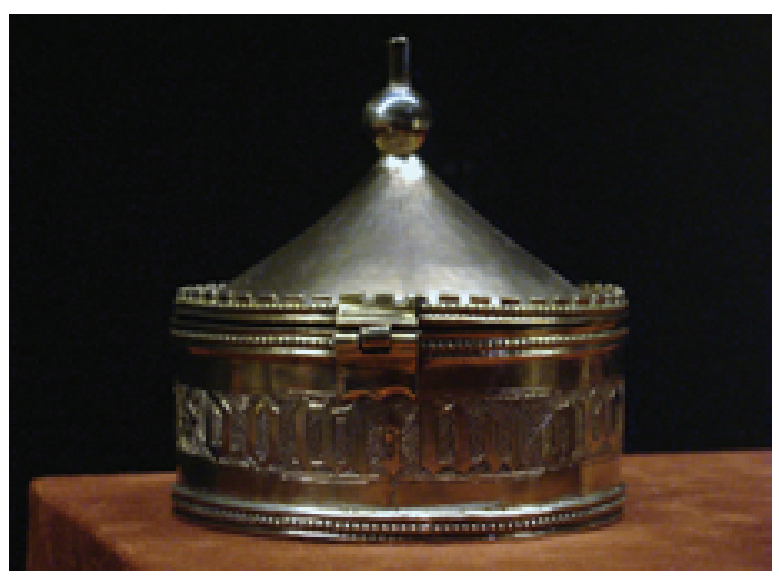

Lám. 7. Invocatio en una píxide de Aldueso. Foto Enrique Campuzano 


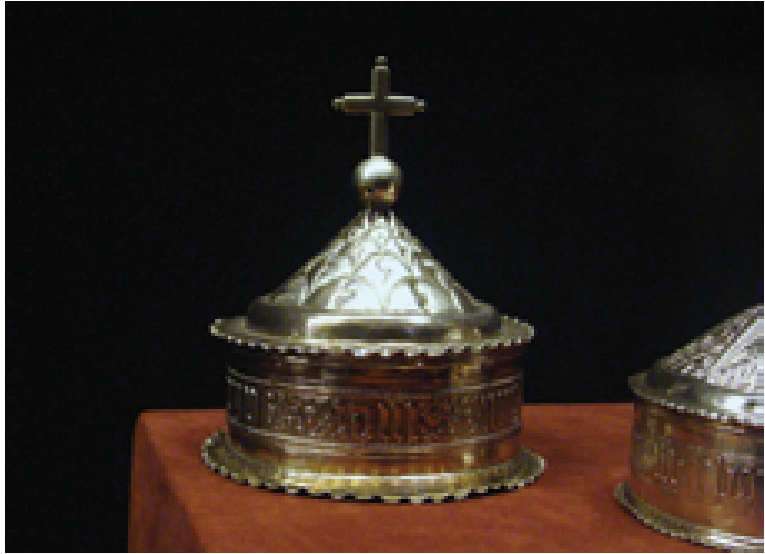

Lám. 8. Invocatio en una píxide de Polientes. Foto Enrique Campuzano

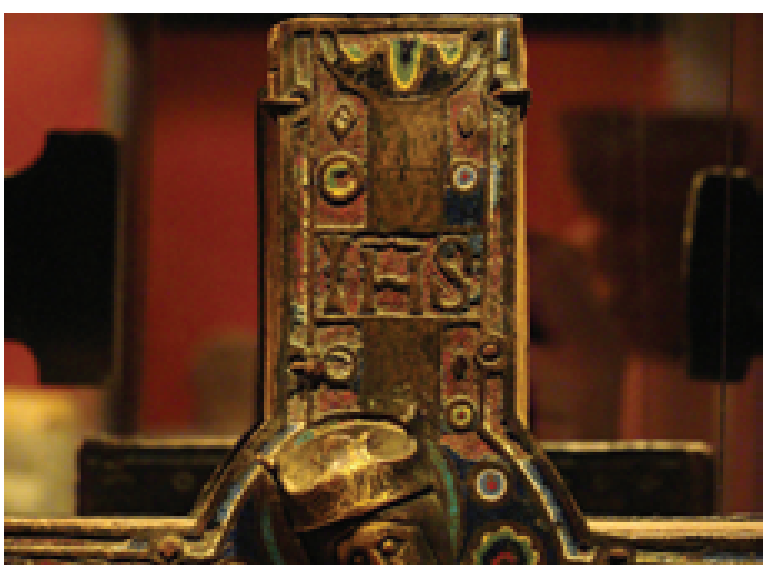

Lám. 10. Invocatio en cruz de Piasca. Foto Enrique Campuzano

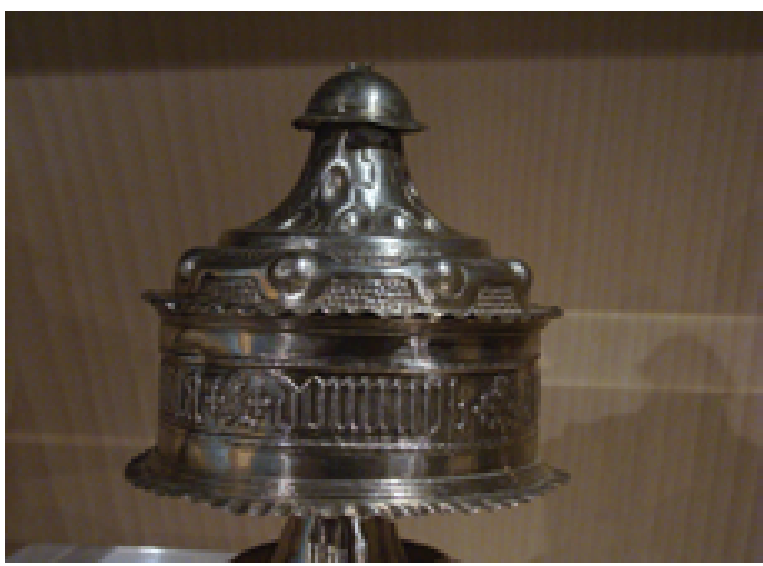

Lám. 12. Invocatio en una píxide de Linares. Foto Enrique Campuzano

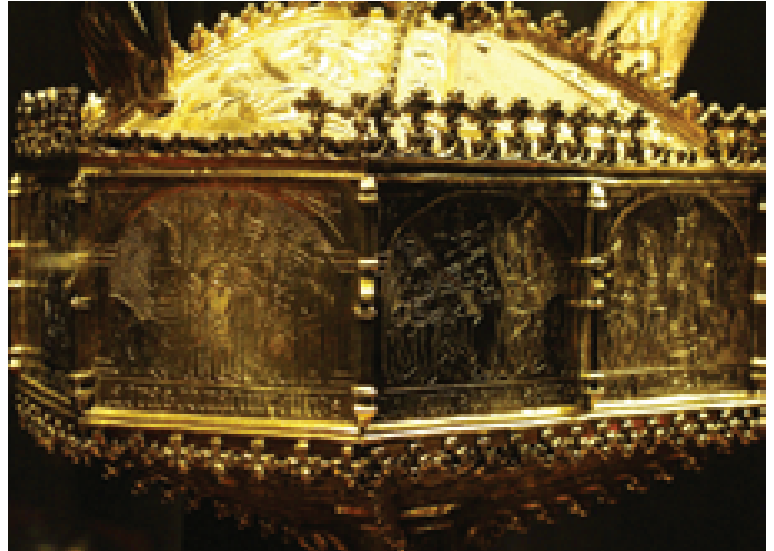

Lám. 9. Donatio en una custodia de Castro Urdiales. Foto Enrique Campuzano

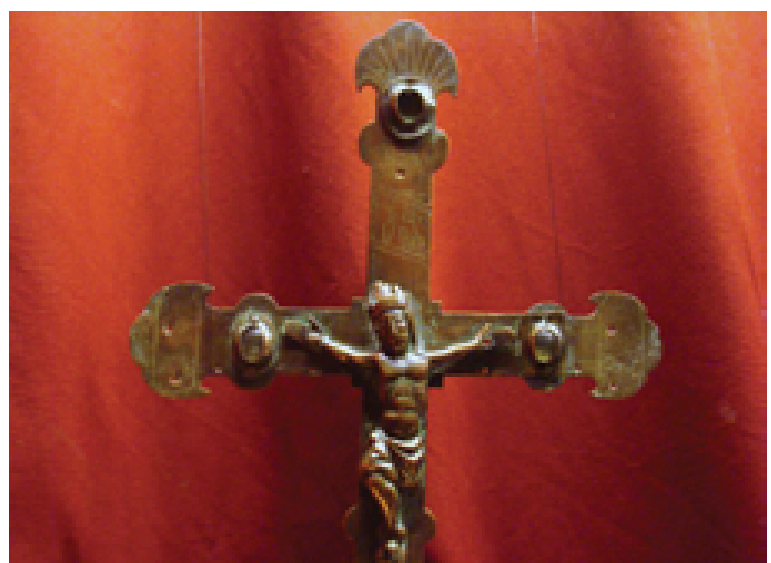

Lám. 11. Invocatio en una cruz de Hoz de Abiada. Foto Enrique Campuzano

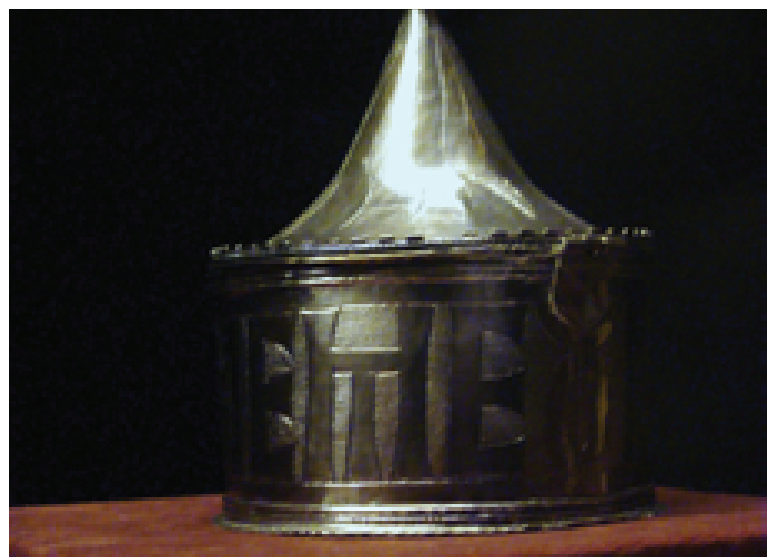

Lám. 13. Invocatio en una píxide de Santa Cruz de Iguña. Enrique Campuzano 